\title{
Staggered contracts and persistence : microeconomic foundations and macroeconomic dynamics
}

\author{
Jean-Pascal Bénassy* \\ CEPREMAP and CNRS $S^{* *}$
}

\section{Introduction}

The purpose of this article is to develop a microfounded type of wage contracts which will allow to introduce wage stickiness into dynamic general equilibrium models in a way which is analytically tractable, and enables to reproduce a few empirical facts in a satisfactory manner. In particular we shall see that these contracts create a propagation mechanism and strong persistence in response to monetary shocks, a feature most often missing in standard RBC models with money.

Our investigation will also help to clarify a "puzzle" arising in current research on contracts and business cycles. A number of authors have recently asked the question of whether staggered wage or price contracts are sufficient by themselves to create a strong propagation mechanism for monetary demand shocks, and the answers are surprisingly different. For example, although their models are of similar nature, Chari, Kehoe, McGrattan (2000) answer negatively, whereas Collard and Ertz (2000) answer positively ${ }^{1}$. Our model will allow to isolate the most salient parameters, and

* I wish to thank Fabrice Collard, Patrick Fève, Jean-Pierre Laffargue, François Langot and the Referees for their comments on earlier versions of this paper. Of course responsibility for any remaining deficiencies is fully mine.

** Address : CEPREMAP, 142 Rue du Chevaleret, 75013 Paris, France.

E-mail : jean-pascal.benassy@ cepremap.cnrs.fr. Telephone:33-1-40778462. Fax: 33-1-44243857.

1 On this issue see also, among others, Ambler, Guay and Phaneuf (1997), Andersen (1998), Ascari (2000), Huang, Liu and Phaneuf (2000), Jeanne (1998) and Yun (1996). Some of these papers combine a price or wage contract with other rigidities. Here we will concentrate on the potential of our contracts to create persistence by themselves. 
clarify the differences.

The first question to ask when building such a model is of course : which contracts? Various types of wage contracts have indeed been developed since the seventies, notably associated with the names of Gray (1976), Fischer (1977), Phelps-Taylor (1977), Phelps (1978), Taylor (1979, 1980) and Calvo (1983). The contracts introduced by Calvo (1983) are particularly interesting for us, because with a single parameter one can describe contracts ranging from full wage flexibility to full rigidity. To be more precise this parameter, say $\gamma$, is the probability that a wage contract survives unchanged until the next period. Each new contract is set on the basis of the information of the current period. So for $\gamma=0$ wages are fully flexible, for $\gamma=1$ they are totally rigid. This parameter $\gamma$ will appear absolutely central for all that follows ${ }^{2}$.

A particularity of Calvo contracts is that, as in Taylor (1979, 1980), the value of the wage set in a particular contract remains constant throughout the duration of the contract. We would like to change this for at least two reasons. The first is empirical : in reality multiyear contracts typically stipulate different wages for different years. The second one is normative : in an inflationary environment, since one would have to pick the same wage for periods with highly different price levels, such contracts could create enormous inefficiencies.

So what we shall do is to construct a new contract which, while keeping the central elegant feature of Calvo contracts, allows the value of the negotiated wages to depend on time. This will solve the two problems above. Moreover these contracts give a degree of persistence similar to that of the original Calvo contracts, so that this positive feature is also maintained.

Two other important characteristics deserve to be stressed : the first is that, within our given contract structure, the values of wage contracts themselves will be derived from the behavior of utility maximizing tradeunions, and not postulated, as is usually the case in most of this literature. The second one is that we shall obtain closed form solutions for both the value of contracts and the resulting macrodynamics. This will enable us to find in particular which parameters are fundamental in the persistence issue, and why various authors have obtained different results.

The plan of the article is the following : section 2 describes the model, section 3 derives the dynamics in the case where all markets clear, section 4 derives the demand for labor, section 5 computes the optimal wage contracts, section 6 studies the macroeconomic dynamics, and notably the output response to monetary shocks.

2 An earlier investigation of similar nature than this paper's was carried out in an insightful article by Ascari (2000). He uses the original Taylor contract with a fixed duration of 2 periods. We shall see below that having $\gamma$, and thus the average length of the contract, as a "free parameter" is important for a full description of the propagation mechanism. 


\section{$2 \quad$ The model}

\subsection{Markets and agents}

The economy studied is a monetary economy with markets for goods at the (average) price $P_{t}$ and markets for labor at the (average) wage $W_{t}$. Goods markets are competitive. The labor markets function under a system of imperfectly competitive labor contracts, which will be detailed below.

The output index $Y_{t}$ is an aggregate of a continuum of output types, indexed by $i \in[0,1]$ :

$$
\log Y_{t}=\int_{0}^{1} \log Y_{i t} d i
$$

Each index $Y_{i t}$ is itself the aggregate of another infinity of output types indexed by $k^{3}$ :

$$
Y_{i t}=\left(\int_{0}^{1} Y_{i k t}^{\theta} d k\right)^{1 / \theta} \quad 0<\theta<1
$$

We may note that this representation differs from the "traditional" one, where only one CES agregator like (2) is assumed. The natural interpretation of our structure is that index $i$ represents sectors, whereas the index $k$ represents firms within these sectors. It is fully natural to assume, as we do, that there is more substitutability within sectors than across sectors.

Now we will further assume that all firms with the same index $i$ face exactly the same situation in terms of wage contracts. This means notably that all firms within a sector, although they compete through prices and wages, negotiate wages at exactly the same time. In the contrary these negotiations need not be synchronized between different sectors. So one main difference between sectors, as we shall see below, is that they will usually have signed different wage contracts at different times.

Finally firm $(i, k)$ has a production function :

$$
Y_{i k t}=Z_{t} N_{i k t}^{a}
$$

where $Z_{t}$ is a technological shock common to all firms.

The representative consumer (we omit the indexes $i$ or $k$ at this stage) works $N_{t}$, consumes $C_{t}$ and ends the period with a quantity of money $M_{t}$. He maximizes the expected value of his discounted utilities, with the following intertemporal utility :

$$
U=\sum \beta^{t}\left[\log C_{t}+\omega \log \frac{M_{\ell}}{P_{t}}-V\left(N_{t}\right)\right]
$$

\footnotetext{
3 We could use the more precise notation $k_{i}$ instead of $k$, but this would complicate the notation without much gain in understanding.
} 
where $V$ is a convex function. At the beginning of period $t$ there is a stochastic multiplicative monetary shock as in Lucas (1972) : money holdings carried from the previous period $M_{t-1}$ are multiplied by the same factor $\mu_{t}$ for all agents, so that the representative household starts period $t$ with money holdings $\mu_{t} M_{t-1}$. His budget constraint in $t$ is thus :

$$
C_{t}+\frac{M_{t}}{P_{t}}=\frac{W_{t}}{P_{t}} N_{t}+\frac{\mu_{t} M_{t-1}}{P_{t}}+\Pi_{t}
$$

where $\Pi_{t}$ are profits distributed.

\subsection{Wage contracts}

Let us now describe the wage contracts. As in Calvo (1983), in each period there is a random draw for all contracts, after which any particular contract will continue unchanged (with probability $\gamma$ ), or be terminated (with probability $1-\gamma$ ). In this last case the corresponding contract wages are set by the workers in each firm on the basis of all information currently available.

Note that our assumption that contracts in the same sector (i.e. with the same index $i$ ) are renegotiated at the same time implicitly means that the random drawings take place sector by sector.

We denote by $W_{t}$ the average wage, and by $X_{s t}$ the wage contract signed in period $s$ to be in effect in period $t$ (as we shall find out below, all workers who sign a new contract in $s$ for period $t$ choose the same wage level, so that we do not need to index $X_{s t}$ by $i$ or $k$ ). The assumption in Calvo was that $X_{s t}$ is independent of $t$ for all $t \geqslant s$. In the contrary we shall assume that these can be different for all periods.

\section{The Walrasian regime}

We shall now, as a benchmark for what follows, compute the Walrasian equilibrium of this economy. In that case all workers have the same wage $W_{t}$, which clears the labor market. Production and employment are the same in all firms and related by:

$$
Y_{t}=Z_{\imath} N_{t}^{\alpha}
$$

The real wage is equal to the marginal productivity of labor:

$$
\frac{W_{t}}{P_{t}}=\alpha \frac{Y_{t}}{N_{t}}
$$


The households maximize the expected value of the utility function (4) subject to the budget constraints (5). The Lagrangean of this maximization program is :

$$
\begin{gathered}
\sum \beta^{t}\left[\log C_{t}+\omega \log \frac{M_{t}}{P_{t}}-V\left(N_{t}\right)\right] \\
+\sum \beta^{t} \lambda_{t}\left[\frac{W_{t} N_{t}}{P_{t}}+\frac{\mu_{t} M_{t-1}}{P_{t}}+\Pi_{t}-C_{t}-\frac{M_{t}}{P_{t}}\right]
\end{gathered}
$$

and the first order conditions :

$$
\begin{gathered}
\lambda_{t}=\frac{1}{C_{t}} \\
\frac{\lambda_{t}}{P_{t}}=\frac{\omega}{M_{t}}+\beta E_{t}\left(\frac{\lambda_{t+1} \mu_{t+1}}{P_{t+1}}\right) \\
V^{\prime}\left(N_{t}\right)=\frac{\lambda_{t} W_{t}}{P_{t}}
\end{gathered}
$$

Combining (9), (10) and the definition $\mu_{t+1}=M_{t+1} / M_{t}$ we obtain :

$$
\frac{M_{t}}{P_{t} C_{t}}=\omega+\beta E_{t}\left(\frac{M_{t+1}}{P_{t+1} C_{t+1}}\right)
$$

which can be solved as :

$$
\frac{M_{t}}{P_{t} C_{t}}=\frac{\omega}{1-\beta}
$$

We see further, combining (7), (9) and (11) that Walrasian employment is constant and equal to $N$, which is given by :

$$
N V^{\prime}(N)=\alpha
$$
labor :

In what follows we shall extensively use the following disutility of

$$
V\left(N_{t}\right)=\xi \frac{N_{t}^{\nu}}{\nu}
$$

in which case the Walrasian level of employment is :

$$
N=\left(\frac{\alpha}{\xi}\right)^{1 / \nu}
$$

and the Walrasian wage:

$$
W_{t}^{*}=\frac{\alpha(1-\beta)}{\omega}\left(\frac{\xi}{\alpha}\right)^{1 / \nu} M_{t}
$$




\section{Wage contracts : the demand for labor}

We shall now begin the study of our model under wage contracts. It is assumed that all goods markets are competitive, but that consumers-workers, possibly through trade-unions, decide on the level of wages in a framework of monopolistic competition, and supply the amount of labor demanded by firms at these wages. In this section we shall derive the demand for labor addressed to consumers.

Here the demand for labor derives from the demand for goods, so we start with this last, one. At any time there is a multiplicity of prices due to the fact that wages are different across firms. Consider first the firms producing final output. For a given aggregate output index $Y_{t}$ they minimize costs, i.e. they solve the following program:

$$
\max P_{t} Y_{t}-\int_{0}^{1} P_{i t} Y_{i t} d i \quad \text { s.t. } \quad \int_{0}^{1} \log Y_{i t} d i=\log Y_{t}
$$

whose solution is :

$$
\begin{gathered}
Y_{i t}=\frac{P_{t} Y_{t}}{P_{i t}} \\
\log P_{t}=\int_{0}^{1} \log P_{i t} d i
\end{gathered}
$$

Now for a given index $Y_{i t}$ firms will similarly minimize costs, i.e. they solve :

$$
\max P_{i t} Y_{i t}-\int_{0}^{1} P_{i k t} Y_{i k t} d k \quad \text { s.t. } \quad\left(\int_{0}^{1} Y_{i k t}^{\theta} d k\right)^{1 / \theta}=Y_{i t}
$$

whose solution is :

$$
\begin{gathered}
Y_{i k t}=Y_{i t}\left(\frac{P_{i k t}}{P_{i t}}\right)^{-1 /(1-\theta)} \\
P_{i t}=\left(\int_{0}^{1} P_{i k t}^{-\theta /(1-\theta)} d k\right)^{-(1-\theta) / \theta}
\end{gathered}
$$

Putting together equations (18) and (20) we obtain the expression of the demand for goods:

$$
Y_{i k t}=\frac{P_{t} Y_{t}}{P_{i t}}\left(\frac{P_{i k t}}{P_{i t}}\right)^{-1 /(1-\theta)}
$$

An important thing to remember for what follows is that, in view of equation (18), all sectors have exactly the same value of sales :

$$
P_{i t} Y_{i t}=P_{t} Y_{t} \quad \forall i
$$


The firm $(i, k)$ competitively maximizes profits $P_{i k t} Y_{i k t}-W_{i k t} N_{i k t}$ subject to production function (3). This yields the usual first order condition :

$$
W_{i k t} N_{i k t}=\alpha P_{i k t} Y_{i k t}
$$

Let us combine this first-order condition with the production function (3) and the demand equation (22). We obtain the demand for labor in firm $(i, k)$ :

$$
N_{i k t}=\left[\frac{\alpha\left(P_{t} Y_{t}\right)^{1-\theta} P_{i l}^{\theta} Z_{t}^{\theta}}{W_{i k t}}\right]^{1 /(1-\alpha \theta)}
$$

\section{Optimal wage contracts}

We shall derive the optimal wage contracts, assuming from now on the particular disutility of labor :

$$
V\left(N_{t}\right)=\frac{\xi N_{t}^{\prime}}{\nu}
$$

The value of contracts signed in period $s$ for periods $t \geqslant s$ is obtained by maximizing the expectation, as of period $s$, of the discounted utility (4) subject to budget constraints (5) and labor demands (25). The following proposition characterizes these contracts :

Proposition 1 : The wage contract $X_{\text {st }}$ signed in $s$ for period t is given by:

$$
X_{s t}=\left(\frac{\xi}{\alpha^{2} \theta}\right)^{1 / \nu} \frac{\alpha(1-\beta)}{\omega}\left[E_{s} M_{t}^{\nu}\right]^{1 / \nu}
$$

Proof : Appendix 1.

We may note that, using equation (17) giving the value of the Walrasian wage $W_{t}^{*}$, equation (27) can be rewritten under the simpler and more intuitive form:

$$
X_{s t}^{\nu}=\frac{1}{\alpha \theta} E_{s}\left(W_{t}^{*}\right)^{\nu}
$$

We thus see that $X_{s t}^{\nu}$ is equal to the expected value in $s$ of $\left(W_{t}^{*}\right)^{\nu}$, multiplied by $1 / \alpha \theta$, i.e. the usual "monopolistic markup" corresponding to the isoelastic labor demand curve (25). 


\section{Macroeconomic dynamics}

Before deriving the macroeconomic dynamics of this model let us briefly summarize the results obtained in the previous sections and appendix $1:$ all consumers have the same income, consumption and money holdings. They differ, however, by their wage and employment level. In any firm the wage level in period $t$ depends only on the date $s$ when it was negotiated, and we denoted by $X_{s t}$ the corresponding wage. Since wages differ across sectors, so do prices, and we find in appendix 1 (formula 63) the value of the price $P_{s t}$ in a sector where the wage is $X_{s t}$ :

$$
P_{s t}=\frac{\left(P_{t} Y_{t}\right)^{1-\alpha}}{Z_{t}}\left(\frac{X_{s t}}{\alpha}\right)^{\alpha}=\frac{1}{Z_{t}}\left[\frac{(1-\beta) M_{t}}{\omega}\right]^{1-\alpha}\left(\frac{X_{s t}}{\alpha}\right)^{\alpha}
$$

\subsection{Output dynamics}

Using formula (13), the equality $C_{t}=Y_{t}$, and going to logarithms, we find that output is given by ${ }^{4}$ :

$$
y_{t}=\log \left(\frac{1-\beta}{\omega}\right)+m_{t}-p_{t}
$$

We thus have to derive the aggregate price $p_{t}$. We first have the general formula (19) :

$$
p_{\ell}=\log P_{t}=\int_{0}^{1} \log P_{i t} d i
$$

Because of the law of large numbers, and in view of the uniform survival rate $\gamma$ for all wage contracts, in period $t$ a proportion $(1-\gamma) \gamma^{t-s}$ of the wage contracts comes from period $s \leqslant t$. The same proportions apply, of course, to prices so that formula (31) is rewritten:

$$
p_{t}=\log P_{t}=(1-\gamma) \sum_{s=-\infty}^{t} \gamma^{t-s} \log P_{s t}
$$

in which we recognize a formula very similar to the corresponding one in Calvo (1983). Inserting (29) into (32) we obtain:

$$
p_{t}=(1-\alpha) \log \left[\frac{(1-\beta) M_{t}}{\omega}\right]-z_{t}-\alpha \log \alpha+\alpha(1-\gamma) \sum_{s=-\infty}^{t} \gamma^{t-s} \log X_{s t}
$$

\footnotetext{
${ }^{4}$ Lowercase letters represent the logarithms of the variables denoted by the corresponding uppercase letters.
} 


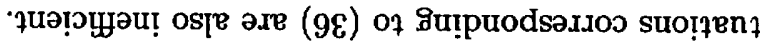

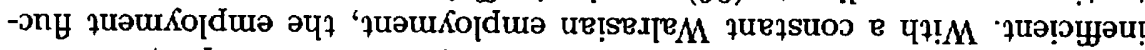

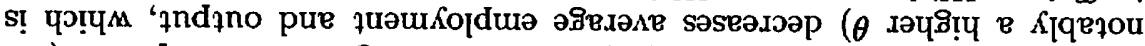

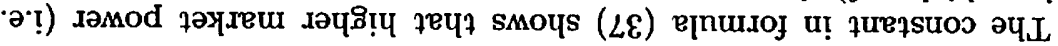

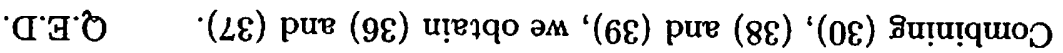

$$
\left(\frac{3}{x}\right) \text { 8от } \frac{n}{\mathrm{~L}}=u \quad:(9 \mathrm{I}) \text { worl MON }
$$

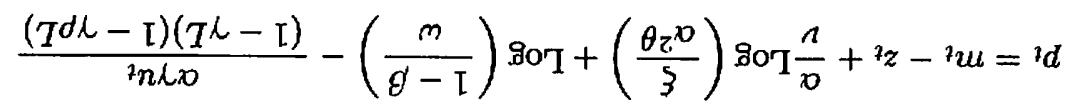

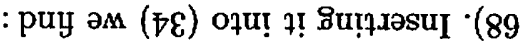

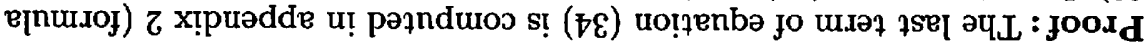

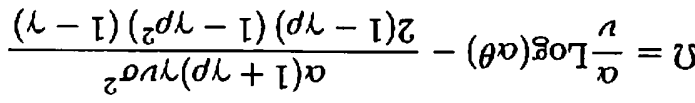

$$
\begin{aligned}
& \mho+\frac{\left(T^{d \Lambda}-\mathrm{I}\right)\left(T^{\lambda}-\mathrm{I}\right)}{{ }^{7} n \mathcal{D} D}+u \delta+{ }^{7} z={ }^{7} \hbar
\end{aligned}
$$

$: f q$

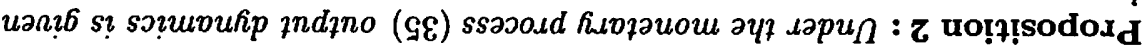

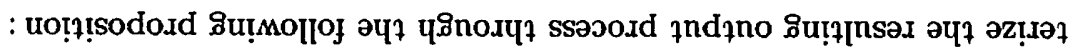

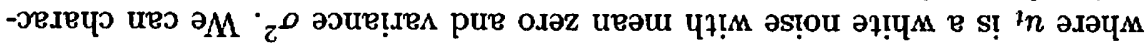

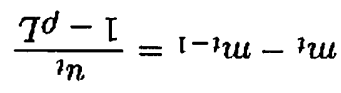

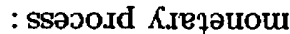

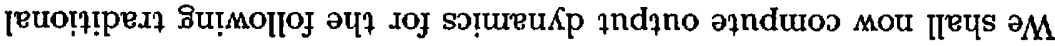

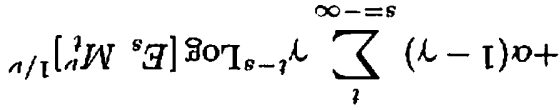

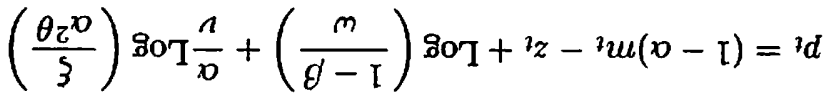

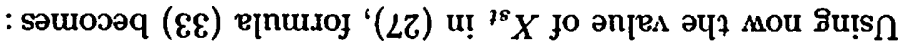




\subsection{Impulse response functions}

Formula (36) shows that the response to a monetary shock can be quite persistent. We can get a first idea of the time profile of this response by computing the impulse response functions of output to a monetary shock. The important parameters are of course $\gamma$ and $\rho$. A value for $\rho$ quite usually found in the literature is $\rho=0.5$. As for $\gamma$, let us first compute the average duration of wage contracts : a contract has a probability $(1-\gamma) \gamma^{j}$ to be still in effect in period $j$, so that the average duration is :

$$
(1-\gamma) \sum_{j=0}^{\infty} j \gamma^{j}=\frac{\gamma}{1-\gamma}
$$

The average duration of wage contracts is usually considered to lie between one and two years. So two impulse responses have been plotted in figures 1 and 2. Both use the value $\rho=0.5$. Figure 1 takes $\gamma=4 / 5$ (which corresponds to a one year, or 4 quarters, duration of contracts), while figure 2 takes $\gamma=8 / 9$ (which corresponds to a two years duration of contracts).

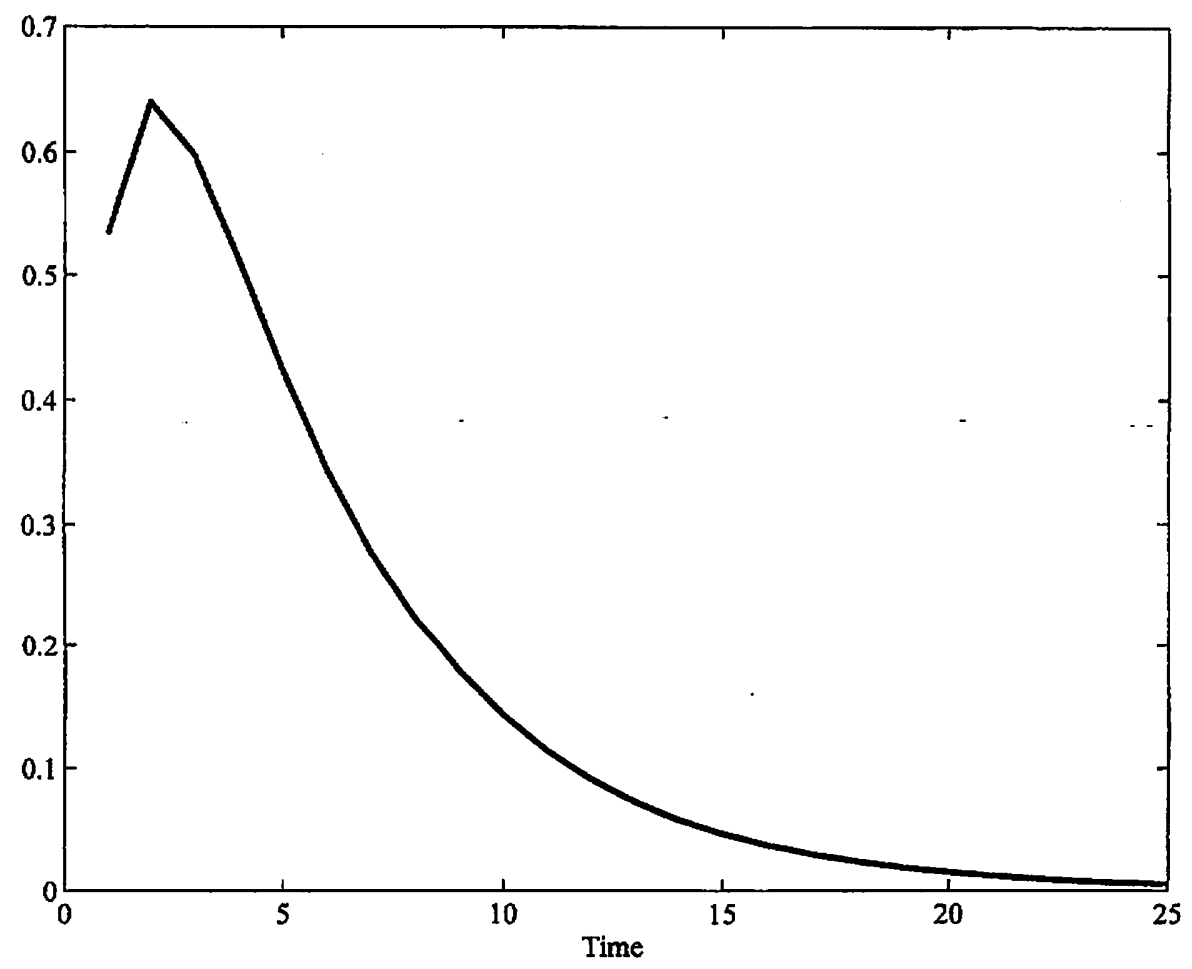

Figure 1 


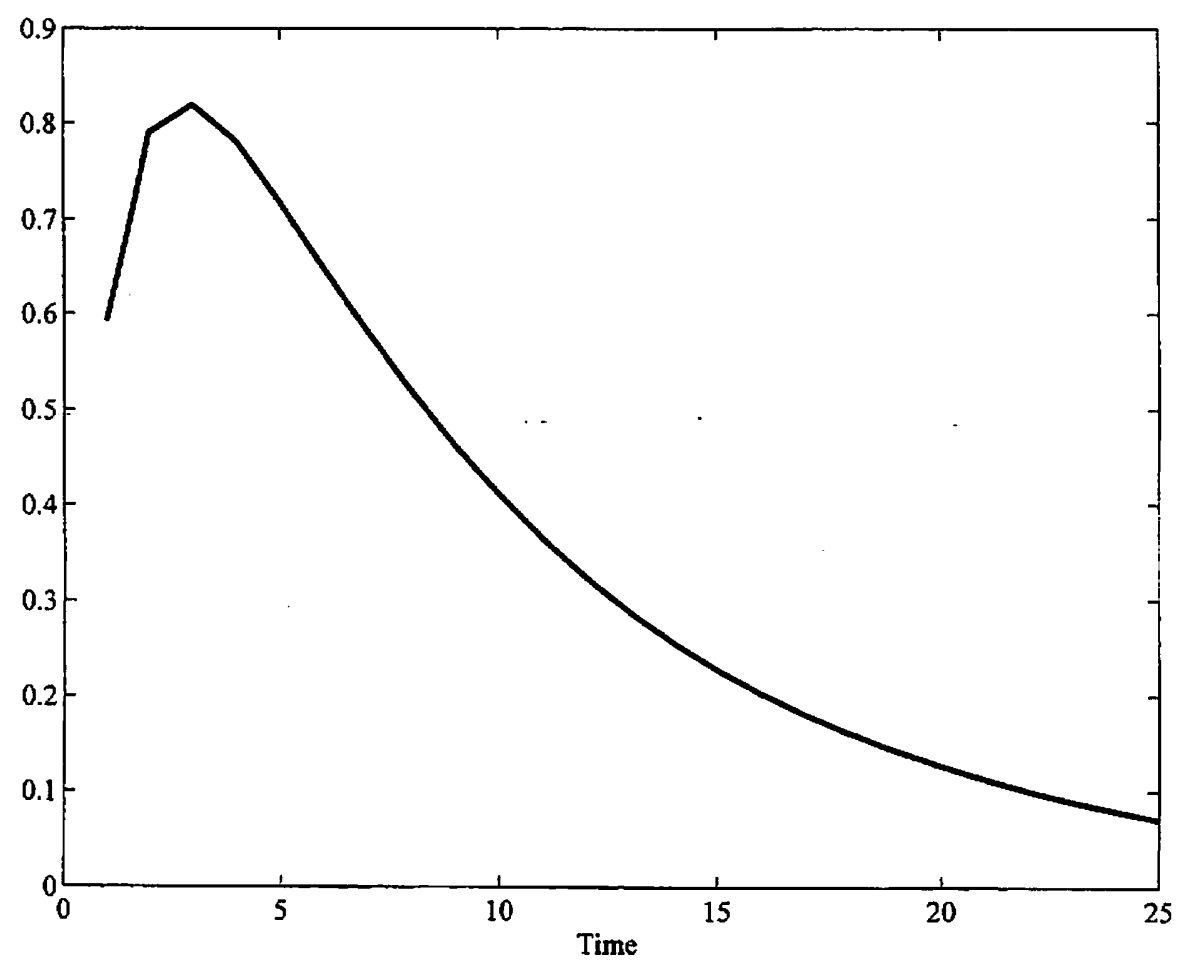

Figure 2

We see that both response functions show persistence, and even display a hump, which is more marked for the 2 years contract case than for the one year contract case.

\subsection{The hump}

Formula (36) suggests, and figures 1 and 2 confirm, that the response of output to a money shock may be first increasing, and then decreasing, giving thus rise to the "hump" which apparently characterizes the actual response to money shocks (Cogley, Nason, 1995). We shall make this more precise through the following proposition, which tells us under which conditions a hump will occur, as well as its timing:

Proposition 3 : Under the monetary process (35) there will be a hump in the response of output to money if:

$$
\gamma>\frac{1}{1+\rho}
$$


In that case the time at which the hump occurs is the integer $\hat{\jmath}$ given by:

$$
\hat{\jmath}<\frac{1}{\log \rho} \log \left(\frac{1-\gamma}{1-\gamma \rho}\right)<\hat{\jmath}+1
$$

Proof : We saw above that, up to a constant :

$$
y_{t}=\frac{\alpha \gamma u_{t}}{(1-\gamma L)(1-\gamma \rho L)}=\frac{\alpha \gamma u_{t}}{1-\rho}\left[\frac{1}{1-\gamma L}-\frac{\rho}{1-\gamma \rho L}\right]
$$

The term of order $j$ is a multiple of :

$$
\gamma^{j}-\rho(\gamma \rho)^{j}
$$

The hump will thus occur for the integer value $j$ such that:

$$
\gamma^{j-1}-\rho(\gamma \rho)^{j-1}<\gamma^{j}-\rho(\gamma \rho)^{j}>\gamma^{j+1}-\rho(\gamma \rho)^{j+1}
$$

These two inequalities are rewritten:

$$
\rho^{j+1}<\frac{1-\gamma}{1-\gamma \rho}<\rho^{j}
$$

Going to logarithms this yields :

$$
j<\frac{1}{\log \rho} \log \left(\frac{1-\gamma}{1-\gamma \rho}\right)<j+1
$$

which is equation (42). Now for this to correspond to an actual hump, the value of $j$ so obtained must be greater than one:

$$
\frac{1}{\log \rho} \log \left(\frac{1-\gamma}{1-\gamma \rho}\right)>1
$$

which yields equation (41).

Q.E.D.

We may give a simple explanation of condition (41) for a humpshaped employment and output response. Intuitively the employment response to a monetary shock $j$ periods after the shock will be proportional to the product of two factors : (a) the proportion of wage contracts remaining, i.e. $\gamma^{j+1}$, (b) the cumulative money shock, taking into account the fact that money increments are autocorrelated, i.e. $1+\rho+\ldots+\rho^{j}$. Now a necessary and sufficient condition for a hump is that the impact at time $j=1$ be greater than the impact at time $j=0$, i.e. that $\gamma^{2}(1+\rho)>\gamma$, which yields condition (41). 


\subsection{The autocorrelations of output variations}

Another stylized fact that traditional models often fail to reproduce is the positive autocorrelations of output variations, at least at short lags (CogleyNason (1995)). We shall consider monetary shocks only (formula 35), and see, via the following proposition, that our model allows to reproduce these positive autocorrelations.

Proposition $4:$ Denote output variations by $\Delta y_{t}=y_{t}-y_{t-1}$. These are autocorrelated in time according to the formula:

$$
\operatorname{Cov}\left(\Delta y_{\ell}, \Delta y_{t-j}\right)=\left[\frac{a^{2} \gamma^{j}}{1-\gamma^{2}}+\frac{b^{2} \zeta^{j}}{1-\zeta^{2}}+\frac{a b\left(\gamma^{j}+\zeta^{j}\right)}{1-\gamma \zeta}\right] \sigma^{2}
$$

where :

$$
\zeta=\gamma \rho \quad a=-\frac{\alpha(1-\gamma)}{1-\rho} \quad b=\frac{\alpha(1-\zeta)}{1-\rho}
$$

\section{Proof : Appendix 3.}

Using formula (49), we can actually compute explicitly autocorrelations at various lags. The autocorrelation at lag one is relatively simple:

$$
\operatorname{Corr}\left(\Delta y_{t}, \Delta y_{t-1}\right)=\frac{\gamma+\gamma \rho+\gamma^{2} \rho-1}{2}
$$

For greater lags, formulas become very rapidly clumsy, but the computer easily generates the autocorrelations profiles. Figure 3 depicts the autocorrelations of output variations at various lags, for the same parameter values as in figure 2 . We see that at low values of the lags, these autocorrelations are indeed positive, as in the data.

\subsection{The propagation puzzle}

We can now with the help of our model and the explicit solutions throw some light on the very different answers given in the literature on the ability of models with contracts to create a propagation mechanism for demand shocks. Propositions 2, 3 and 4 clearly show that, for that issue, the most important parameters are $\gamma$ and $\rho$, so we organize the discussion around them.

Consider, as an example, the articles by Chari, Kehoe and McGrattan (2000) and Collard and Ertz (2000), whose results are particularly different. The first article estimates $\rho=0.57$, the second $\rho=0.495$, so that the difference will come only marginally from that parameter. Let us now move to the parameter $\gamma$, which, as we shall see, is at the root of the differences. 


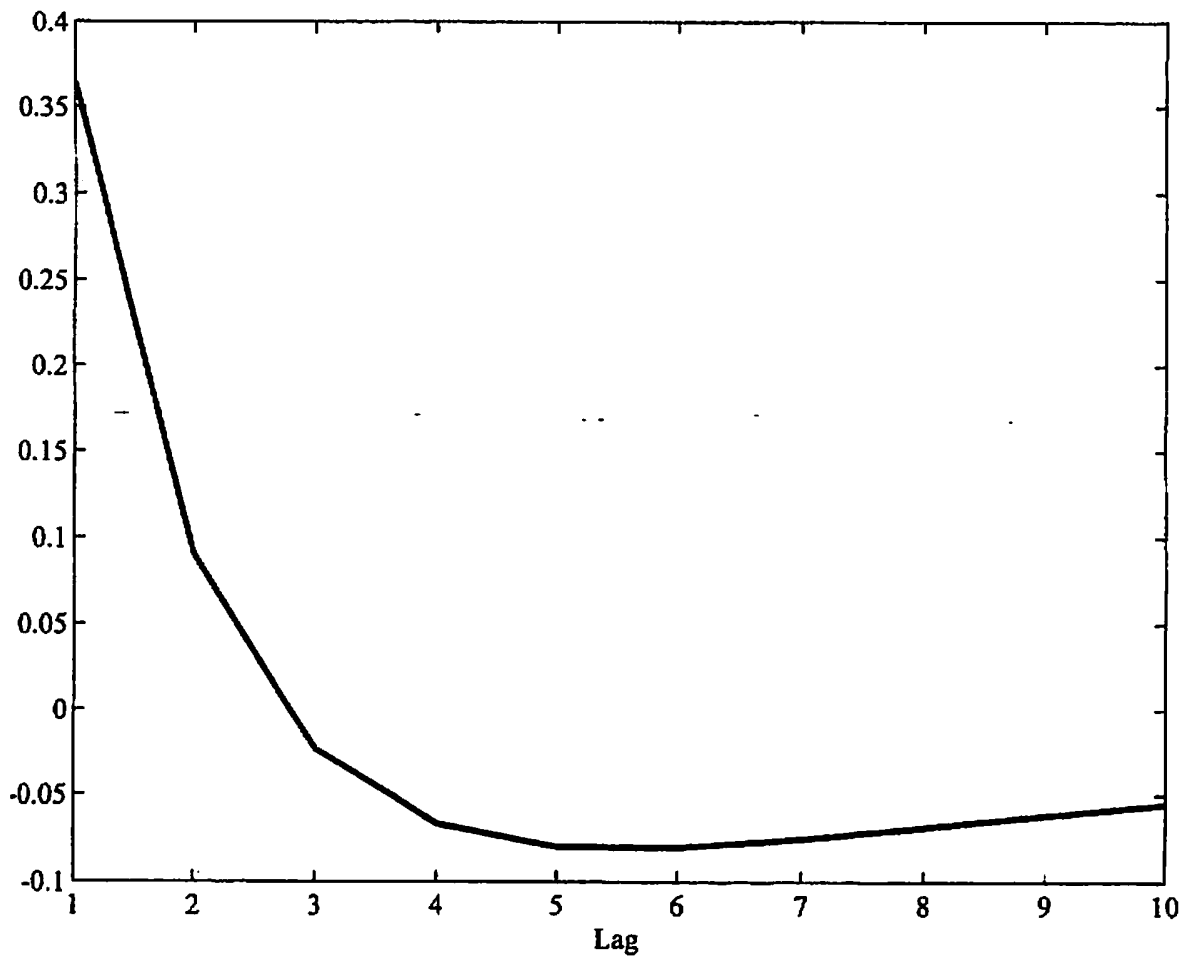

Figure 3

In order to make the discussion more intuitive, we actually take as the parameter of discussion the average length of contracts, equal to $\gamma /(1-\gamma)$.

Now Collard and Ertz (2000) study wage contracts of the Calvo (1983) type. Their central parameter is thus very similar to the $\gamma$ of this article. As a result, they show that one year or two years contracts lead to strong propagation and a hump, a result completely in accordance with the results of this article.

At the opposite, Chari, Kehoe and McGrattan (2000) consider price contracts with a duration of 13 weeks (i.e. a quarter), and find that their model delivers much less persistence than in reality. They consider indeed the "halflife" of the process, i.e. the time it takes for the effect of a shock to be half of the impact effect. They report a halfife of 10 quarters in reality, while using our formulas with their parameters we find less than 2 quarters, obviously much too low. Clearly by choosing contracts of a very low duration they did not find a propagation mechanism in a quite predictable manner ${ }^{5}$.

5 A further cause for their finding of a low persistence is that they use price contrects which, for the same duration, often lead to less persistence than wage contracts (Andersen, 1998). 


\section{Conclusion}

In this paper we developed a new form of wage contracts with maximizing trade-unions, and integrated it into a rigorous business cycle model. We were able to obtain closed form solutions throughout, for both the optimal wage contracts and the resulting macroeconomic dynamics. We found that we could generate a strong propagation mechanism, and in particular produce a hump-shaped response of output to monetary shocks, and positive autocorrelations of output variations at short lags. These are features that have been observed in the data, and which traditional RBC models often failed to reproduce.

From our closed form solutions it appears also that the parameter $\gamma$ describing the "survival rate" of contracts, which is the basis of Calvo's (1983) and our contract, is also a central parameter in explaining the capacities of the model to create an endogenous propagation mechanism. In particular many differences in the literature on this subject seem to mainly boil down to different values in the (implicit or explicit) value of this parameter.

\section{Appendix 1 : Proof of Proposition 1}

Since we do not know yet whether all consumers will sign the same contracts in the same period, we denote by $X_{i k s t}$ the contract signed by consumer $(i, k)$ at time $s$, to be in effect in period $t$. In order to determine $X_{i k s t}$, consumer $(i, k)$ maximizes his discounted expected utility. We shall consider here only the terms corresponding to the contracts signed in $s$ and still in effect at time $t$, so the relevant wage is $X_{i k s t}$. Since contracts have a probability $\gamma$ to survive each period, the contract signed in $s$ has a probability $\gamma^{t-s}$ to be still in effect in period $t$, and the consumer will thus maximize the expected value in $s$ of the following discounted utility :

$$
\sum_{t \geqslant s} \beta^{t-s} \gamma^{t-s}\left[\log C_{i k t}+\omega \log \frac{M_{i k t}}{P_{t}}-\frac{\xi N_{i k t}^{\nu}}{\nu}\right]
$$

subject to the budget constraints in each period :

$$
C_{i k t}+\frac{M_{i k t}}{P_{t}}+I_{i k t}=\frac{X_{i k s t}}{P_{t}} N_{i k t}+\frac{\mu_{t} M_{i k t-1}}{P_{t}}+\Pi_{t}
$$

and the equations giving the demand for labor (formula 25) :

$$
\begin{gathered}
N_{i k t}=\Phi_{i t} X_{i k s t}^{-1 /(1-\alpha \theta)} \\
\Phi_{i t}=\left[\alpha P_{i t}^{\theta} Z_{t}^{\theta}\left(P_{t} Y_{t}\right)^{1-\theta}\right]^{1 /(1-\alpha \theta)}
\end{gathered}
$$


Inspecting this maximization problem, we first see that all consumers sharing the same index $i$ face exactly the same circumstances, so that in equilibrium we will have :

$$
X_{i k s t}=X_{i s t} \quad \forall k
$$

So all consumers in the same sector $i$ have the same wage and employment. Now in view of equations (23) and (24), in any sector $i$ :

$$
W_{i t} N_{i t}=\alpha P_{i t} Y_{i t}=\alpha P_{t} Y_{t}
$$

We see that all consumers, whatever the sector $i$ they are in, have the same income, and therefore the same consumption and money holdings (but they differ, of course, in their wages and employment levels):

$$
C_{i k t}=C_{t} \quad M_{i k t}=M_{t} \quad \forall i, k
$$

Consumers indexed by $(i, k)$ maximize (52) subject to (53) and (54). Let us insert the value of $N_{i k t}$ (equation 54) into (52) and (53). Taking into account (58) the corresponding Lagrangean is written (we omit the terms that will not be used) :

$$
\sum_{t \geqslant s} \beta^{t-s} \gamma^{t-s}\left\{\log C_{t}-\frac{\xi}{\nu} \Phi_{i t}^{\nu} X_{i k s t}^{-\nu /(1-\alpha \theta)}+\lambda_{i k t}\left[\frac{\Phi_{i t}}{P_{t}} X_{i k s t}^{-\alpha \theta /(1-\alpha \theta)}-C_{t}\right]\right\}
$$

Maximization in $C_{t}$ yields :

$$
\lambda_{i k t}=\frac{1}{C_{t}}
$$

Now when choosing in period $s$ the various contract wages $X_{i k s t}, t \geqslant s$, the consumer maximizes the expected value in $s$ of the maximand (59). The part concerning $X_{i k s t}$ is thus, suppressing unimportant constants :

$$
E_{s}\left[\frac{\Phi_{i t}}{P_{t} C_{t}} X_{i k s t}^{-\alpha \theta /(1-\alpha \theta)}-\frac{\xi}{\nu} \Phi_{i t}^{\nu} X_{i k s t}^{-\nu /(1-\alpha \theta)}\right]
$$

The first order condition for this program is :

$$
\alpha \theta X_{i k s t}^{-1 /(1-\alpha \theta)} E_{s}\left(\frac{\Phi_{i t}}{P_{t} C_{t}}\right)=\xi X_{i k s t}^{-\nu /(1-\alpha \theta)-1} E_{s}\left(\Phi_{i l}^{\nu}\right)
$$

We now have to compute the value of $\Phi_{i \ell}$ (equation 55). Combining equations (3) and (57), we find that:

$$
P_{i t}=\frac{\left(P_{t} Y_{t}\right)^{1-\alpha}}{Z_{t}}\left(\frac{W_{i t}}{\alpha}\right)^{\alpha}=\frac{\left(P_{t} Y_{t}\right)^{1-\alpha}}{Z_{t}}\left(\frac{X_{i s t}}{\alpha}\right)^{\alpha}
$$


Inserting this into (55) yields :

$$
\Phi_{i t}=\alpha P_{t} Y_{t} X_{i s t}^{\alpha \theta /(1-\alpha \theta)}
$$

We now insert (64) into (62) using $X_{i k s t}=X_{i s t}$ (equation 56). Equation (62) then simplifies as:

$$
\alpha^{2} \theta X_{i s t}^{\nu}=\xi E_{s}\left(\alpha P_{t} Y_{t}\right)^{\nu}
$$

We see that the value of $X_{i s t}$ is independent of the sector $i$, and we denote it as $X_{s t}$. Now from equation (13), which is still valid, we know that :

$$
P_{t} Y_{t}=\frac{1-\beta}{\omega} M_{t}
$$

Inserting (66) into (65) we find:

$$
\alpha^{2} \theta X_{s t}^{\nu}=\xi\left[\frac{\alpha(1-\beta)}{\omega}\right]^{\nu} E_{s} M_{t}^{\nu}
$$

which yields directly (27).

\section{Appendix 2}

Lemma 1 : Assume the monetary process (35). Then:

$$
\begin{gathered}
(1-\gamma) \sum_{j=0}^{\infty} \gamma^{j} \log \left[E_{t-j} M_{t}^{\nu}\right]^{1 / \nu}= \\
m_{t}-\frac{\gamma u_{t}}{(1-\gamma L)(1-\gamma \rho L)}+\frac{(1+\gamma \rho) \gamma \nu \sigma^{2}}{2(1-\gamma \rho)\left(1-\gamma \rho^{2}\right)(1-\gamma)}
\end{gathered}
$$

Proof : Since the monetary variables are lognormal, we use the standard formula :

$$
\log \left[E_{t-j}\left(M_{t}^{\nu}\right)\right]^{1 / \nu}=E_{t-j}\left(m_{t}\right)+\nu \frac{\operatorname{Var}_{t-j}\left(m_{t}\right)}{2}
$$

with :

$$
m_{t}=m_{t-j}+\frac{u_{i-j+1}}{1-\rho L}+\ldots \ldots+\frac{u_{t}}{1-\rho L}
$$

Let us compute in turn the mean and variance :

$$
E_{t-j} m_{t}=m_{t-j}+\frac{\rho u_{t-j}}{1-\rho L}+\ldots . .+\frac{\rho^{j} u_{t-j}}{1-\rho L}=m_{t-j}+\frac{\rho\left(1-\rho^{j}\right) u_{t-j}}{(1-\rho)(1-\rho L)}
$$




$$
\begin{aligned}
m_{t}-E_{t-j} m_{t} & =\left(1+\rho+\ldots \rho^{j-1}\right) u_{t-j+1}+\left(1+\rho+\ldots \rho^{j-2}\right) u_{t-j+2}+\ldots \ldots+u_{t} \\
& =\frac{1-\rho^{j}}{1-\rho} u_{t-j+1}+\frac{1-\rho^{j-1}}{1-\rho} u_{t-j+2}+\ldots+u_{t} \\
\operatorname{Var}_{t-j}\left(m_{t}\right) & =\sigma^{2}\left[\left(\frac{1-\rho^{j}}{1-\rho}\right)^{2}+\left(\frac{1-\rho^{j-1}}{1-\rho}\right)^{2}+\ldots+1\right] \\
& =\frac{\sigma^{2}}{(1-\rho)^{2}}\left[j-\frac{2 \rho\left(1-\rho^{j}\right)}{1-\rho}+\frac{\rho^{2}\left(1-\rho^{2 j}\right)}{1-\rho^{2}}\right]
\end{aligned}
$$

Combining (69), (71) and (73), we obtain :

$$
\begin{aligned}
& \log \left[E_{t-j}\left(M_{t}^{\nu}\right)\right]^{1 / \nu}=m_{t-j}+\frac{\rho\left(1-\rho^{j}\right) u_{t-j}}{(1-\rho)(1-\rho L)} \\
& +\frac{\nu \sigma^{2}}{2(1-\rho)^{2}}\left[j-\frac{2 \rho\left(1-\rho^{j}\right)}{1-\rho}+\frac{\rho^{2}\left(1-\rho^{2 j}\right)}{1-\rho^{2}}\right]
\end{aligned}
$$

So the expression in (68) is equal to:

$$
\begin{aligned}
& (1-\gamma) \sum_{j=0}^{\infty} \gamma^{j} \log \left[E_{t-j} M_{t}^{\nu}\right]^{1 / \nu}=(1-\gamma) \sum_{j=0}^{\infty} \gamma^{j}\left[m_{t-j}+\frac{\rho\left(1-\rho^{j}\right) u_{t-j}}{(1-\rho)(1-\rho L)}\right] \\
& \quad+(1-\gamma) \sum_{j=0}^{\infty} \gamma^{j} \frac{\nu \sigma^{2}}{2(1-\rho)^{2}}\left[j-\frac{2 \rho\left(1-\rho^{j}\right)}{1-\rho}+\frac{\rho^{2}\left(1-\rho^{2 j}\right)}{1-\rho^{2}}\right]
\end{aligned}
$$

Let compute separately the first and second terms :

$$
\begin{gathered}
(1-\gamma) \sum_{j=0}^{\infty} \gamma^{j}\left[m_{t-j}+\frac{\rho\left(1-\rho^{j}\right) u_{t-j}}{(1-\rho)(1-\rho L)}\right]=m_{t}-\frac{\gamma u_{t}}{(1-\gamma L)(1-\gamma \rho L)} \\
(1-\gamma) \sum_{j=0}^{\infty} \gamma^{j} \frac{\nu \sigma^{2}}{2(1-\rho)^{2}}\left[j-\frac{2 \rho\left(1-\rho^{j}\right)}{1-\rho}+\frac{\rho^{2}\left(1-\rho^{2 j}\right)}{1-\rho^{2}}\right]= \\
\frac{(1+\gamma \rho) \gamma \nu \sigma^{2}}{2(1-\gamma \rho)\left(1-\gamma \rho^{2}\right)(1-\gamma)}
\end{gathered}
$$

Combining (75), (76) and (77) we find (68). 


\section{Appendix 3 : Proof of Proposition 4}

We saw above that output is given by, up to a constant :

$$
y_{t}=\frac{\alpha \gamma u_{t}}{(1-\gamma L)(1-\gamma \rho L)}
$$

Consequently output variations $\Delta y_{t}$ are given by :

$$
\Delta y_{t}=\frac{\alpha \gamma(1-L) u_{t}}{(1-\gamma L)(1-\gamma \rho L)}=\left[\frac{a}{1-\gamma L}+\frac{b}{1-\zeta L}\right] u_{t}
$$

with :

$$
\zeta=\gamma \rho \quad a=-\frac{\alpha(1-\gamma)}{1-\rho} \quad b=\frac{\alpha(1-\zeta)}{1-\rho}
$$

so :

$$
\begin{gathered}
\Delta y_{t}=a \sum_{i=0}^{\infty} \gamma^{i} u_{t-i}+b \sum_{i=0}^{\infty} \zeta^{i} u_{t-i} \\
\Delta y_{t-j}=a \sum_{k=0}^{\infty} \gamma^{k} u_{t-j-k}+b \sum_{k=0}^{\infty} \zeta^{k} u_{t-j-k}
\end{gathered}
$$

To compute the covariance between $\Delta y_{t}$ and $\Delta y_{t-j}$ we only keep in the expression of $\Delta y_{t}$ the values of the lag above $j$ :

$$
\Delta y_{t}=a \sum_{i=j} \gamma^{i} u_{t-i}+b \sum_{i=j} \zeta^{i} u_{t-i}=a \gamma^{j} \sum_{k=0}^{\infty} \gamma^{k} u_{t-j-k}+b \zeta^{j} \sum_{k=0}^{\infty} \zeta^{i} u_{t-j-k}
$$

Putting together formulas (82) and (83) we obtain :

$$
\operatorname{Cov}\left(\Delta y_{t}, \Delta y_{t-j}\right)=\frac{a^{2} \gamma^{j}}{1-\gamma^{2}}+\frac{b^{2} \zeta^{j}}{1-\zeta^{2}}+\frac{a b\left(\gamma^{j}+\zeta^{j}\right)}{1-\gamma \zeta}
$$

\section{Bibliographie}

Ambler, S., A. Guay and L. Phaneuf (1997), "Wage contracts and labor adjustment costs as internal propagation mechanisms", U.Q.A.M., Montréal.

Andersen, T.M. (1998), "Persistency in sticky price models", European Economic Review, vol. 42, pp. 593-603.

Ascari, G. (2000), "Optimising agents, staggered wages and persistence in the real effects of money shocks", The Economic Journal, vol. 110, pp. 664-686. 
Bénassy, J.-P. (1995), "Money and wage contracts in an optimizing model of the business cycle", Journal of Monetary Economics, vol. 35, pp. 303-315.

Calvo, G. (1983), "Staggered prices in a utility-maximizing framework", Journal of Monetary Economics, vol. 12, pp. 383-398.

Chari, V.V., P.J. Kehoe and E.R. McGrattan (2000), "Sticky price models of the business cycle : can the contract multiplier solve the persistence problem ?", Econometrica, vol. 68, pp. 1151-1179.

Cogley, T. and J.M. Nason (1995), "Output dynamics in real-business-cycle models", American Economic Review, vol.85, pp. 492-511.

Collard, F. and G. Ertz (2000), "Stochastic nominal wage contracts in a cash-in-advance model", Recherches Économiques de Louvain, vol. 66, pp. 281-301.

Fischer, S. (1977), "Long term contracts, rational expectations and the optimal money supply rule", Journal of Political Economy, vol. 85, pp. 191-205.

Gray, J.-A. (1976), "Wage indexation : a macroeconomic approach", Journal of Monetary Economics, vol. 2, pp. 221-235.

Huang, K., Z. Liu and L. Phaneuf (2000), "On the transmission of monetary policy shocks", U.Q.A.M., Montréal.

Jeanne, O. (1998), "Generating real persistent effects of monetary shocks: How much nominal rigidity do we really need ?", European Economic Review, vol. 42, pp. 1009-1032.

Phelps, E. (1978), "Disinflation without recession : adaptive guideposts and monetary policy" Weltwirtschaftliches Archiv, vol. 114, pp. 783-809.

Phelps, E. and J.B. Taylor (1977), "Stabilizing powers of monetary policy under rational expectations", Journal of Political Economy, vol. 85, pp. 163-190.

Taylor, J. B. (1979), "Staggered wage setting in a macro model", American Economic Review, vol. 69, pp. 108-113.

Taylor, J. B. (1980), "Aggregate dynamics and staggered contracts", Journal of Political Economy, vol. 88, pp. 1-23.

Yun, T. (1996), "Nominal price rigidity, money supply endogeneity and business cycles", Journal of Monetary Economics, vol 37, pp. 345370 . 